\title{
GESTÃO ESCOLAR: OS PRINCIPAIS DESAFIOS DO DIRETOR DE ESCOLA PÚBLICA MUNICIPAL
}

\section{ARTIGO ORIGINAL}

SANDES, Cleize Araújo ${ }^{1}$

ANDRADE, Thaís Oliveira ${ }^{2}$

SANDES, Cleize Araújo. ANDRADE, Thaís Oliveira. Gestão Escolar: Os principais desafios do diretor de Escola Pública Municipal. Revista Científica Multidisciplinar Núcleo do Conhecimento. Ano 05, Ed. 10, Vol. 12, pp. 123-136. Outubro de 2020. ISSN: 2448-0959, Link de acesso: https://www.nucleodoconhecimento.com.br/educacao/escola-publicamunicipal

\section{RESUMO}

Toda escola necessita de um corpo diretivo que consiste em uma equipe com funções específicas de modo a gerir suas atividades englobando os âmbitos pedagógicos e administrativos da instituição de ensino. O diretor é nesse caso, um importante elemento da instituição, pois sua grande responsabilidade em aliar todos os eixos escolares o mantém em destaque principalmente em relação aos resultados de

${ }^{1}$ Graduada em Pedagogia e Graduada em Letras Vernáculas, pela Universidade Estadual de Santa Cruz (UESC), especialista em Psicopedagogia Clínica, Institucional e Hospitalar pela Faculdade Santo Agostinho, especialista em Gestão Escolar pela Faculdade Dom Alberto e diretora escolar na Escola Municipal Professor Osvaldo Ramos em llhéus/BA.

${ }^{2}$ Graduada em Pedagogia e Letras Vernáculas pela Universidade Estadual de Santa Cruz (UESC) e mestranda em Estudos Africanos, Povos indígenas e Cultura Negra pela Universidade do Estado da Bahia - UNEB. Coordenadora Pedagógica pela Prefeitura Municipal de São Francisco do Conde. 
aprendizagem, no entanto, essa obrigação deveria ser diluída com outros atores diretivos, mas a falta desses configura-se em um dos desafios que se apresenta em sua função. Para ratificar algumas questões foi realizado um estudo de caso com visitas e entrevistas a instituições escolares no município de llhéus onde foi possível constatar que os desafios são em sua maioria muito semelhantes e o abandono a esses profissionais atinge muitas vezes sua autoestima e confiança no que faz. Todo trabalho aqui apresentado foi baseado principalmente nas bibliografias de Heloísa Luck (2018) e Libâneo (1994), por serem autores com extensa linha de pesquisa e inúmeras contribuições educacionais ao discorrerem com assertividade sobre o papel do diretor e como a gestão democrática configura-se em uma prática de apoio a esse profissional diante de todas as atribuições que the são dadas. Percebe-se que as dificuldades são muitas e que é necessária a busca de estratégias e quem sabe uma política pública que viesse a somar com as escolas e seu papel educacional.

Palavras chave: Gestão Escolar, desafios, Escola Pública.

\section{INTRODUÇÃO}

O presente artigo surgiu da necessidade de se entender quais são as principais dificuldades encontradas por um diretor de escola pública municipal, bem como buscar ainda, possíveis soluções para amenizar tais dificuldades. É certo que os gestores de escolas municipais da educação básica enfrentam diferentes desafios, a cada ano diferente atribuições são destinadas ao mesmo profissional que muitas vezes não possui uma equipe completa ou até mesmo condições básicas para desenvolver seu trabalho, ficando sobrecarregado e tendo que assumir diferentes funções.

O trabalho de um gestor escolar é de fundamental importância para a prática pedagógica e também para alcançar o produto da escola, como afirma Paro (2012), em seu estudo sobre a administração escolar, trata-se da apropriação da cultura pelos alunos, por isso, sua participação em todas as instâncias escolares deve se configurar em rotina. A sensibilidade e técnica desse profissional permeiam todas as ações e passam a delimitar o perfil da instituição. 
São inúmeros os desafios que um gestor escolar da educação pública encontra durante seu período a frente de uma escola, então de que forma esse profissional pode através de um trabalho participativo buscar alternativas para gerir sua unidade escolar de modo a obter melhores resultados no ensino? Através do estudo do caso buscaram-se informações e possíveis soluções para alguns problemas e a pesquisa por autores que são referência nesse assunto foram essenciais, trazendo assim o conhecimento de que é possível encontrar alguns auxílios para o gestor.

Considerando alguns dos problemas encontrados através da pesquisa realizada, é possível perceber que o trabalho participativo é ponto crucial para a gestão, a busca por apoiadores na instituição também é importante, além disso, o olhar do poder público precisa ser direcionado para as escolas a fim de oferecer condições dignas e pessoas qualificadas para o trabalho, assim, a oferta de verbas para que sejam realizadas ações básicas na escola devem ser consideradas durante todo ano letivo.

Refletir sobre o papel da escola como órgão responsável pela educação de um povo, torna possível perceber e entender que o diretor é o agente que une todas as esferas na instituição e por isso, cabe a ele ter clareza sobre suas responsabilidades de modo a criar um ambiente que forme cidadãos críticos, reflexivos, autônomos, conscientes de seus direitos e deveres apesar dos obstáculos que se apresentam. Entender que o papel diretivo pode auxiliar na busca por possíveis soluções para aprimoramento do ensino e desenvolvimento do aluno como sujeito de direitos é de fundamental importância na construção de uma sociedade mais justa e igualitária.

Para entender melhor essa problemática foi realizado um estudo de caso que contou com pesquisa de campo, observações e entrevistas com alguns diretores escolares do ensino fundamental no município de llhéus na Bahia de modo a diagnosticar quais são os principais desafios que esses gestores enfrentam no dia a dia e quais problemas mais se apresentam no cotidiano escolar dificultando o trabalho de gestão desses profissionais. Após esse primeiro momento foi realizada também uma pesquisa bibliográfica onde foi possível perceber que o exercício de uma gestão participativa auxiliaria na maior parte dos problemas levantados. 


\section{GESTÃO ESCOLAR E O PAPEL DO DIRETOR NA ESFERA PÚBLICA MUNICIPAL}

A história da gestão escolar no Brasil tem início na década de $\mathrm{XX}$ quando os pedagogos formados recebiam formação teórica juntamente com a Administração Empresarial visto que as instituições de ensino eram tratadas como empresas. A visão de Gestão foi fruto de longas lutas iniciadas na década de trinta com o Manifesto dos Pioneiros da Educação, que buscavam uma maior cientificidade na educação brasileira.

A função do diretor escolar, em tese, seria a de gerir os aspectos administrativos da instituição além de participar ativamente das atividades pedagógicas. Desta forma, esse profissional perpassa por todas as esferas da unidade escolar e cabe a ele também interligar todas as áreas realizando uma gestão coesa dos segmentos de professores, pais, alunos, funcionários e sociedade. É sem dúvida uma atividade de grande importância que reflete a visão deste profissional e modela sua gestão. Para isso, é fundamental a visão participativa do seu trabalho, pois segundo Luck:

É do diretor da escola a responsabilidade máxima quanto à consecução eficaz da política educacional do sistema e desenvolvimento plenos dos objetivos educacionais, organizando, dinamizando e coordenando todos os esforços nesse sentido e controlando todos os recursos para tal. (LÜCK, 2004, p.32).

As ações de um gestor escolar são muito parecidas com a gestão de outras áreas como a empresarial ou qualquer outro segmento, no entanto, ela adquire um aspecto extremamente singular, visto que o aspecto humano permeia toda a ação escolar. Desta forma, o diretor precisa cumprir suas atribuições, mas não pode perder de vista o lado humano da administração.

Assim como outro gestor, o diretor escolar precisa motivar sua equipe e estabelecer o entrosamento para a efetivação do trabalho produtivo. Todos os segmentos precisam estar alinhados e apesar de funções distintas tanto os funcionários como os professores precisam se enxergar como parte de um todo buscando resultados 
positivos, trabalhando em equipe e mantendo-se motivados, tendo a visão no objetivo maior que é a aprendizagem e desenvolvimento do aluno.

Define-se, pois, a gestão democrática como o processo em que se criam condições para que os membros de uma coletividade não apenas tomem parte, de forma regular e contínua, de suas decisões mais importantes, mas assumam responsabilidade por sua implementação. Isso porque democracia pressupõe muito mais que tomar decisões: envolve a consciência de construção de conjunto da unidade social e de seu processo de melhoria contínua como um todo. (LUCK, 2018, p. 57)

No momento que o diretor precisa aliar o setor administrativo com o pedagógico encontram-se os primeiro desafios da gestão. Faltam em grande parte das escolas, profissionais de todas as áreas como supervisor, secretário, porteiro entre outros colaboradores e desta forma, o diretor precisa assumir também essas funções o que acaba sobrecarregando sua jornada de trabalho e resultados. Por se tratar de escolas públicas, existem muitas vezes, carência financeira e pessoal levando este profissional a assumir uma função que não é a dele.

A influência política ainda é uma realidade e por vezes atrapalha o andamento do trabalho resultando na contratação de profissionais que muitas vezes não apresentam habilidades efetivas para a função de educar. E aqui cabe suscitar a indicação por esse fim do próprio diretor escolar, abafando o processo democrático desde a sua nomeação.

Ao propiciar a indicação sem outros mecanismos que coíbam a imposição de vontades particulares de pessoas ou grupos, a nomeação pura e simples por autoridade estatal encerra sempre um alto grau de subjetividade. Isso propicia um sem número de injustiças e irregularidades, já que não existe um critério objetivo, controlável pela população, que, além de garantir o respeito aos interesses do pessoal escolar e dos usuários, possa também evitar o favorecimento ilícito de pessoas, situação que fere o princípio de igualdade de oportunidades de acesso ao cargo de candidatos. (PARO, 2003, p. 18).

Neste contexto, apesar da indicação não ser a melhor forma de escolha para o gestor, já que é pensado em uma gestão democrática, ao diretor cabe atuar extraindo o melhor de sua equipe através da motivação a fim de promover mudanças significativas no ambiente de trabalho. Esse é um desafio de grandes proporções, pois manter os 
profissionais motivados apesar da realidade que se configura, é na verdade um ato de superação diária.

A interação eficaz entre líderes e os seus liderados é a base, portanto, para a criação da confiança entre ambos. Os líderes têm que ser confiáveis, previsíveis e justos nas suas relações. Esta, por sua vez, se faz a partir de um processo de comunicação aberto, pelo qual os líderes constroem a confiança ao dar poder aos seus liderados. Ao se trabalhar o desenvolvimento de um estilo eficaz de relacionamento com liderados, "líderes fortalecem o seu pessoal e a instituição, podendo criar um legado que irá durar por muito tempo. (GARDNER, 1986, apud LÜCK, 2012, p. 41).

É de fundamental importância que o gestor educacional possua equilíbrio diante das inúmeras situações desafiadoras do seu ambiente de trabalho, sua função muitas vezes é acrescida de atribuições diversas devendo alternar entre atitudes de autoridade e flexibilidade. Ele precisa dar conta da parte administrativa e humana buscando apoio na sua equipe apesar da falta de pessoas, estrutura física insuficiente e poucos recursos financeiros. Desta forma, é muito difícil para o diretor fazer um bom trabalho, pois além de se apresentar um profissional sobrecarregado, ainda precisa manter a motivação da equipe tendo claro seu princípio de educação e valores, exercendo uma gestão participativa e democrática.

De acordo com a Lei 3.150 de 20 de dezembro de 2004, que dispõe sobre a gestão democrática do ensino público da rede municipal,

Art. 5 Compete ao diretor:

I - Conhecer as principais normas e leis que regem a educação, no âmbito nacional, estadual e municipal;

II - Definir as normas regimentais sobre pessoal e corpo discente incluindo os sansões pelo não cumprimento das mesmas;

III - Responsabilizar-se pela aplicação da avaliação de desempenho dos servidores;

IV - Assegurar a operacionalização das ações previstas no PDE - Plano de Desenvolvimento da Escola e na Proposta Pedagógica, assim como fazer as intervenções, quando necessário e constatado através de instrumentos periódicos de avaliação (ILHÉUS, 2004). 
Esse artigo está presente na Lei Orgânica Municipal e trata de forma sucinta as atribuições do gestor municipal, no entanto, cada capítulo pode ser interpretado e destrinchado de modo a explicar melhor cada função existente. É importante que toda comunidade escolar saiba as reais funções do diretor para que assim compreenda e possa auxiliar e participar de forma efetiva no andamento da unidade entendendo que os resultados finais são de responsabilidade de toda equipe escolar e comunidade.

Já o Plano de Cargos, Carreira e salários do Magistério Público Municipal de llhéus, Lei ํo 3.346 de 27 de maio de 2008, não especifica o papel do diretor escolar, sua citação quanto a esse profissional refere-se aos requisitos básicos para pleitear o cargo,

Art. 70 São requisitos para pleitear o cargo de diretor e vice-diretor das unidades escolares:

I - Para diretor e vice-diretor das unidades escolares de ensino da Educação Infantil e do Ensino Fundamental I:

a) Licenciatura plena em curso de Pedagogia ou normal superior;

b) Experiência mínima de 04 (quatro) anos na docência da Educação Infantil ou Ensino Fundamental I da rede municipal de llhéus.

II - Para diretor e vice-diretor das unidades escolares de Fundamental II:

a) Licenciatura plena em cursos de Pedagogia ou outro de Faculdade de Filosofia ou Educação;

b) Experiência mínima de 04 (quatro) anos na docência da Educação Infantil ou Ensino Fundamental II da rede Municipal de Ilhéus (PCCS, 2008, p. 7).

Mais à frente no Capítulo IV dessa mesma lei, é possível ter acesso às atribuições do exercício do magistério, no entanto, há apenas o artigo 48 que discorre sobre as atribuições do professor e os artigos 50 e 51 que detalham o que compete ao supervisor e orientador consecutivamente. Essa divisão de tarefas onde não aborda a função diretiva torna imprecisa nesse documento à responsabilidade do gestor, fator incoerente na luta por direitos de uma classe. 


\subsection{O PAPEL DA GESTÃO ESCOLAR PEDAGÓGICA}

Cabe ao gestor escolar o papel mais complexo da estrutura de ensino. É esse profissional que precisará articular o trabalho em diferentes aspectos em prol de um determinado fim que é o aprendizado dos alunos. A ele cabe participar ativamente da elaboração de documentos que garantam o ensino e possam facilitar a maneira como os alunos aprendem. Juntamente com o supervisor escolar, o diretor deve basear-se no que preza o Projeto Político Pedagógico da instituição e traçar metas e ações para minimizar as dificuldades de aprendizagem que por ventura se apresentem na escola. A criação de projetos trimestrais, atividades diferenciadas, aulas de campo são alguns recursos que o diretor precisa vislumbrar para sua Unidade Escolar de modo a diversificar a maneira de ensinar e assim alcançar um maior número de alunos estimulando a criatividade na equipe e criando condições para que todos possam trabalhar juntos através de uma comunicação clara e valores éticos.

A gestão pedagógica é, de todas as dimensões da gestão escolar, a mais importante, pois está mais diretamente envolvida com o foco da escola que é o de promover a aprendizagem e a formação dos alunos...

Constitui-se como a dimensão para a qual todas as demais convergem, uma vez que está se refere ao foco principal do ensino que é a atuação sistemática e intencional de promover a formação e a aprendizagem dos alunos, como condição para que desenvolvam as competências sociais e pessoais necessárias para sua inserção proveitosa na sociedade e no mundo do trabalho, numa relação de benefício recíproco. Também para que se realizem como seres humanos e tenham qualidade de vida. (LÜCK, 2006, p.95).

O trabalho pedagógico da escola precisa estar em constante movimento, visto que os alunos têm mudado com o passar do tempo, seus interesses também são outros e desta forma, a educação precisa acompanhar essas mudanças. A tecnologia encontra-se em todo lugar, um planejamento estático não irá alcançar o objetivo educacional e à escola cabe também se adequar a essa realidade que engloba todo o mundo. 
...é de suma importância que reine na escola um clima de coletividade, onde cada aluno é incentivado a colaborar com o bem estar comum e fortalecer traços de coletividade.

O ambiente escolar, assim, pode concorrer para suscitar o amor pela escola, a dedicação aos estudos, com reflexos sensíveis no aproveitamento escolar do aluno. (LIBÂNEO, 1994, p. 116).

Assim, a orientação do trabalho pedagógico precisa englobar todas essas questões, além de envolver toda a equipe nas tomadas de decisões e, a gestão democrática perpassa por ações que proporcionem o envolvimento de todos e desta forma, a responsabilização pelos sucessos e pelas falhas que possam surgir. Esse modo de fazer pedagógico traz a ideia de pertencimento e ajuda a criar indivíduos participativos, criadores e conscientes.

\subsection{GESTÃO ESCOLAR ADMINISTRATIVA}

Cabe ao diretor gerir de forma eficaz os recursos financeiros prestando conta a toda comunidade escolar, também precisa gerir pessoas e manter um ambiente equilibrado e saudável para alunos, pais e funcionários. Cabe a ele manter a linha pedagógica de acordo com o sistema de ensino ao qual seu município pertence integrando comunidade, governo e instituição na busca de uma educação de qualidade.

Cabe ao gestor ainda, manter os documentos da escola organizados, zelar pelos equipamentos e manter o ambiente físico limpo e agradável. Também precisa garantir o acesso e permanência dos alunos na escola, a qualidade do ensino ofertado, a dinâmica escolar, a gestão de toda equipe sob uma administração ética e respeitosa a todos que convivem e frequentam o meio escolar.

Considerando os recursos financeiros, a Constituição Federal de 1988 estipula uma porcentagem que deve ser respeitada tanto pela União, Estados e Municípios para efeito de aplicação na educação básica pública sendo dividida da seguinte forma:

Art. 212. A União aplicará, anualmente, nunca menos de dezoito, e os Estados, o Distrito Federal e os Municípios vinte e cinco por cento, no mínimo, da receita resultante de impostos, compreendida a proveniente 
de transferências, na manutenção e desenvolvimento de ensino. (CONSTITUIÇÃO, 1988).

Sendo assim, para além da verba federal destinada diretamente às escolas, o município deve contribuir com o apoio financeiro necessário para a manutenção e efetivação das atividades pedagógicas escolares e manutenção da estrutura física dos prédios, possibilitando melhores condições para todos os atores escolares incluindo a gestão.

As atribuições administrativas trazem uma analogia entre a administração escolar e a administração empresarial apresentando semelhanças e oposições. O uso do conceito da administração é válido para entender o papel primordial que deve ser encarado também no âmbito escolar que, segundo Paro (2012, p. 25) "é a utilização racional de recursos para a realização de fins determinados", desta forma, a escola precisa utilizar-se dessa ideia central para aperfeiçoar seus resultados construindo uma educação eficaz e comprometida com seus alunos.

Assim, diante da necessidade de se promoverem a eficiência e a produtividade da escola, não há razão para que esta, entendida também como organização, não possa pautar-se, na consecução de seus objetivos, por procedimentos administrativos análogos àqueles que tanto êxito alcançam na situação empresarial. (PARO, 2012, p. 17-18).

Partindo do uso da função primeira da administração, a gestão escolar deve utilizarse do seu princípio sem perder de vista a importância da sua postura democrática, retirando toda concepção autoritária que possa vir a ter o colóquio empresarial, pois,

A escola, assim, só será uma organização humana e democrática se a fonte desse autoritarismo, que ela identifica como sendo a administração (ou a burocracia, que é o termo que os adeptos dessa visão preferem utilizar), for substituída pelo espontaneísmo e pela ausência de todo tipo de autoridade ou hierarquia nas relações vigentes na escola. (PARO, 2012, p. 18).

A face administrativa da gestão escolar considerando seu fim deve trazer como resultado imediato, segundo Luck (2018, p. 64) "a criação de um ambiente e de um conjunto de ações pedagógicas eficazes para a promoção da formação dos alunos e 
sua aprendizagem", ou seja, mais uma vez o fim de todos os esforços no âmbito educacional deve estar voltado para o desenvolvimento cognitivo e social dos alunos.

\section{PESQUISA DE CAMPO COM DIRETORES DA REDE MUNICIPAL DO MUNICÍPIO DE ILHÉUS - BA}

Sabendo da importância em realizar uma pesquisa para obter informações sobre o que foi pretendido conhecer, foi escolhido o Estudo de Caso através de observações do ambiente escolar, entrevista e visita de campo, assim, foi possível obter material suficiente para análise e conclusões acerca do tema proposto.

Ao sair em campo para apurar as reais dificuldades e desafios encontrados pelos diretores de algumas escolas públicas, ficou claro que as questões levantadas por esses profissionais são muito parecidas. Os diretores quase sempre esbarram nos mesmos problemas que parecem muitas vezes sem solução, atrapalhando seu trabalho e consequentemente seus resultados. Ao visitar cinco diferentes escolas foi possível constatar a veracidade das respostas desses diretores e entender a insatisfação por não conseguirem realizar um trabalho de excelência apesar do esforço.

\subsection{INSTRUMENTOS DA PESQUISA}

O estilo de pesquisa realizado foi o Estudo de Caso que utilizou de visita, entrevista e observações do ambiente escolar. As visitas aconteceram em cinco escolas dentre as quais, três atendem o Ensino Fundamental I, e duas escolas atendem ao Fundamental II, totalizando com isso, cinco diretores além de acompanhamento com vice-diretores, secretários e supervisores que também fazem parte da equipe dessas unidades e coadunaram com as queixas dos diretores em todos os aspectos. Utilizamos um questionário, entrevistas semiestruturadas, análise do espaço, diálogos com os agentes escolares e observação do trabalho da equipe gestora.

Esse trabalho aconteceu durante $o$ ano de dois mil e dezenove e contou com duas visitas semanais em dias alternados com encontros com diretores e equipe diretiva no 
período de quatro meses consecutivos. Além das entrevistas e conversas, foi possível participar dos momentos de planejamento com professores, equipe gestora e supervisores e também nos foi possibilitado participar das reuniões da gestão que aconteceram em duas unidades a cada quinze dias e em três outras unidades um encontro ao mês. Todos esses encontros corroboraram para a coleta de dados e análise in loco da realidade dessas escolas.

Após realizar a pesquisa, conversar com os gestores escolares e constatar que os desafios são realmente significativos e reais, foi o momento de analisar as respostas e compará-las entre si percebendo que diferentes escolas do nível Fundamental I e II perpassam por dificuldades muito parecidas. Basicamente são situações que infelizmente o diretor precisa enfrentar, pois sua atuação perpassa por todos os setores da unidade escolar.

O principal desafio desses gestores é realmente a falta de recursos básicos para o desenvolvimento do seu trabalho. São ações que precisam ser tomadas e que necessitam de verbas, apoio e planejamento governamental. O que se percebe é um apoio insuficiente a esse profissional em sua unidade onde ele precisa mobilizar e incentivar sua equipe para que projetos e ações pedagógicas aconteçam.

Através da realização da pesquisa e observação do andamento escolar nas unidades visitadas foi possível perceber que os gestores buscam alternativas para que a escola funcione da melhor maneira, no entanto, há entraves muito parecidas entre as diferentes escolas os quais podemos enumerar da seguinte forma:

1. Falta de recurso financeiro;

2. Falta de pessoal;

3. Falta de apoio municipal;

4. Cobranças excessivas por resultados;

5. Sobrecarga de trabalho;

6. Baixo salário;

7. Estrutura física deteriorada;

8. Falta de reconhecimento; 


\section{Sensação de impotência.}

Essas dificuldades acabam por afetar o lado emocional do diretor, pois muitas vezes ele se sente impotente e desmotivado, configurando em uma situação quase irônica se for considerar esse profissional como o grande motivador da sua equipe. Muitos adocem ou desistem da função pedindo sua exoneração já que não percebe que seu trabalho evolui. Poucas escolas contam com o apoio do Colegiado de Pais para fiscalizar e cobrar ações do município, trabalhando sozinha com poucos recursos, acaba por oferecer resultados insuficientes trazendo baixa qualidade de ensino.

A gestão administrativa também esbarra em dificuldades pela falta de pessoal para exercer determinadas funções e como a escola não pode parar, muitas vezes, o próprio diretor desempenha tarefas que não deveria, surge como isso a sobrecarga de trabalho e não raras vezes, é esse profissional que arca com despesas da instituição também. Reparos na estrutura física muitas vezes são custeados pelo gestor para que a escola continue funcionando.

Os processos de gestão e administração da escola implicam uma ação coordenada da direção, coordenação pedagógica e professores, cada um cumprindo sua responsabilidade no conjunto da ação escolar. Os processos de participação democrática incluem não apenas o envolvimento coletivo na tomada de decisões, como também os meios de articulação da escola com órgãos de administração do sistema escolar e com as famílias. (LIBÂNEO, 1994, p. 45).

Cabe aqui lembrar que o papel da escola é fundamental para a construção de uma sociedade mais igualitária e a educação pública precisa agir fortemente para garantir esse fim.

Os objetivos, conteúdos e métodos das escolas públicas devem corresponder às exigências econômicas, sociais e políticas de cada época histórica, no que diz respeito a conquista de uma democracia efetiva para os grupos sociais majoritários da sociedade. Ao delimitar da escola pública democrática é necessário levarmos em conta as características de sua clientela hoje, analisando criticamente a escola de ontem e a escola de hoje, a quem serviu no passado e a quem deve servir hoje. 
A escola pela qual devemos lutar hoje visa o desenvolvimento científico e cultural do povo, preparando as crianças e jovens para a vida, para o trabalho e para a cidadania, através da educação geral, intelectual e profissional. (LIBÂNEO, 1994, p. 44).

Ao refletir sobre essa passagem de Libâneo, é possível considerar o verdadeiro papel da educação que embora seja fundamentalmente importante, não consegue cumprir sua função social visto que a escola por vezes necessita do básico para oferecer uma educação de qualidade com princípios de igualdade para todos. Os desafios são muitos e aos gestores cabem inúmeras atribuições e pouco ou nenhum apoio.

A maioria das escolas visitadas não possuem coordenador e orientador pedagógico, com isso o diretor se torna responsável também para realizar os momentos de planejamento semanal (AC) com os professores e atender aos pais que procuram a instituição para saber sobre a vida escolar de seus filhos, além do tempo desprendido para resolver situações de atrito entre alunos e questões de indisciplina. Com isso, muito do trabalho administrativo fica atrasado ou são levados para casa para serem feitos no final de semana. Outra questão é a falta de pessoal para limpeza, portaria e até mesmo para serviço de secretaria. Em uma das escolas a diretora não dispunha de uma equipe, era apenas ela que realizava todo trabalho escolar de direção, coordenação, orientação e secretaria.

A questão financeira também é um problema recorrente em todas as unidades, muitos projetos não são realizados por falta de verba, e por se tratar de escolas periféricas, não há a possibilidade de ajuda financeira das famílias. A parte estrutural também é outro agravante, infiltrações, telhado quebrado, banheiros sucateados, mobiliário insuficiente, enfim, em algumas unidades faltava literalmente o básico para uma escola em funcionamento.

Desta forma, através da pesquisa e visitas in loco ficou evidenciado que as demandas entre essas escolas municipais se assemelham, bem como as dificuldades e esforços dos gestores. A busca por uma gestão democrática esbarra nas incongruências burocráticas e parceria do poder público frente aos desafios que cada unidade apresenta. Apesar de muito parecidas as barreiras precisariam ser consideradas na 
sua individualidade e ações eficazes precisam ser tomadas no sentido de auxiliar o gestor em seu trabalho e propiciar condições para um ambiente digno para os alunos e equipe escolar. Frente a essa realidade, percebe-se que a mobilização familiar, poderia vir a ser um fator decisivo na melhoria do ensino em âmbito administrativo e pedagógico.

\section{CONSIDERAÇÕES FINAIS}

A gestão escolar exige um profissional qualificado e ciente das suas atribuições e responsabilidades. Os desafios são múltiplos e muitos deles difíceis de serem superados, por isso o diretor escolar precisa ainda assim, manter uma postura de líder e incentivar sua equipe diariamente, estando disposto a assumir seu papel e não raro a função de outros profissionais. Apesar de não haver obrigatoriedade em desempenhar tais funções, é dever do diretor manter e garantir o funcionamento da escola garantindo o ensino a todos.

A lei sindical não mostra detalhadamente as atribuições desse profissional, o que impossibilita a compreensão de outras demandas, apenas a Lei Municipal 3.150/2004 prevê muito rapidamente as atribuições do gestor escolar. A situação financeira da escola também é garantida pela verba federal que cada escola possui, além da garantia pela Constituição Federal de complemento pelo órgão municipal, como visto anteriormente. Essa realidade expõe a fragilidade do sistema educacional, bem como o desafio enfrentado pelo gestor de escolas públicas.

Apesar de o diretor saber qual sua função e buscar exercê-la, ele precisará se preparar para a gestão financeira, de recursos humanos, de conflitos, de infraestrutura, buscar parcerias, entre outras funções que o sobrecarregam e para o qual não foi preparado pelos cursos de licenciatura, por isso, a prática é que faz realmente o gestor saber o que de fato é o ato de gerir com tão poucos recursos e alinhar suas ações de modo a garantir uma gestão participativa, que poderá ajudá-lo, estimulando a equipe a cooperar nas tomadas de decisões. A sua postura deve coadunar com sua prática e ter metas bem definidas com estratégias para alcançálas, envolvendo toda comunidade escolar, pais e alunos, incentivando, ouvindo e 
buscando estratégias cada vez mais precisas para garantir o ensino e aprendizagem e mudança na realidade desses alunos.

O papel do diretor é muito complexo, ele é o elo de todas as esferas em sua unidade e sua responsabilidade é imensurável. Esse profissional precisa estar envolvido em todos os eixos escolares dotados de perseverança e obstinação para manter a obrigatoriedade da escola em oferecer o melhor para seus alunos, desenvolvendo meios de ampliar sua compreensão de mundo e agir sobre sua realidade social.

\section{REFERÊNCIAS}

\section{Ação Integrada: Administração Supervisão e Orientação}

Educacional. Petrópolis, 22ª ed., p.32, 2004.

A escola participativa: o trabalho de gestor escolar. Rio de Janeiro RJ: DP\&A, 4를. ed., p.15, 2005.

BRASIL. Constituição (1988). Constituição da República Federativa do Brasil. Brasília, DF: Senado Federal: Centro Gráfico, 1988.

ILHÉUS, Lei № 3150 de 20 de dezembro de 2004. Disponível em https://leismunicipais.com.br Acesso em 28 jul. 2020.

ILHÉUS, Lei № 3.346 de 27 de maio de 2008. Plano de Cargos, Carreira e Salários do Magistério Público Municipal de llhéus. Ilhéus, p. 7, maio 2008.

LIBÂNEO, J. C. Didática.74, 128 p. Coleção magistério. º grau. Série formação do professor), São Paulo: Cortez, 1994.

. Liderança em gestão escolar. Petrópolis: Vozes, 2012.

LÜCK, H. A gestão participativa na escola. 11 ed. Rio de Janeiro RJ: Vozes, 2013.

PARO, V. H. Administração Escolar: introdução crítica. 17. ed. São Paulo: Cortez, 2012. 
PARO, V. H. Eleição de Diretores: a escola pública experimenta a democracia. $2^{\circ}$ ed. São Paulo: Xamã, 2003.

Enviado: Agosto, 2020.

Aprovado: Outubro, 2020. 